\title{
PROCESSO DE DESENVOLVIMENTO DE CADEIRA DE RODAS PARA BANHO VOLTADA PARA IDOSOS COM MOBILIDADE REDUZIDA
}

\author{
Millena Soares do Nascimento (UNIVERSIDADE FEDERAL DE ALAGOAS) miihsdn@ gmail.com \\ Vinicius de Souza Vieira (UNIVERSIDADE FEDERAL DE ALAGOAS) vinicius-9@ hotmail.com \\ Thamyres de Oliveira Lourenço (UNIVERSIDADE FEDERAL DE ALAGOAS) thamyreslo39@gmail.com \\ Juliana Donato de Almeida (UNIVERSIDADE FEDERAL DE ALAGOAS) juliana.donato@fau.ufal.br
}

\begin{abstract}
Resumo
Com o avançar dos anos, a musculatura humana tende a ter um decréscimo na sua força, o que ocasiona a redução da mobilidade. Denomina-se mobilidade reduzida a condição de movimentos limitados, que podem ser provocados por idade, deficiência ou doença. Nesse contexto estão inseridas as pessoas idosas, que por conta dos movimentos limitados requerem uma atenção especial ou adaptações nos ambientes. Este trabalho apresenta o processo de desenvolvimento de uma cadeira de rodas para banho voltada o referido público, descrevendo as etapas do projeto, que foi iniciado com uma pesquisa desk e finalizado com a apresentação da solução final, de forma a apresentar o detalhamento da metodologia híbrida utilizada, as análises, materiais utilizados, a geração de alternativas e o detalhamento da alternativa escolhida.
\end{abstract}

Palavras-Chaves: Mobilidade reduzida; projeto de objeto; cadeira de rodas para banho.

\section{Introdução}

O Brasil está se tornando um país com grande número de idosos, de acordo com as projeções realizadas pelo Instituto Brasileiro de Geografia e Estatística (IBGE). Ao que tudo indica no ano de 2060, uma grande parcela da população brasileira será de pessoas com mais de 60 anos. Atualmente, são 20,6 milhões de idosos, o que representa 10,8\% da população e no ano de 2060, esse número representará $26,7 \%$ do total. Esses dados apontam para a necessidade de uma maior atenção ao mercado destinado ao referido público, principalmente ao que diz respeito aos produtos que assegurem o bem-estar. Todavia, observa-se que o mercado atual não está preparado para atender tais demandas, pois os produtos encontrados não suprem as carências identificadas, principalmente nos quesitos de material, resistência e estética.

Com o avançar dos anos o corpo humano não é mais o mesmo, e isso acarreta um decréscimo na qualidade de vida. Esse decréscimo é derivado das reações do corpo, que ao decorrer têm 
uma diminuição na capacidade respiratória, na capacidade cardíaca, na diminuição da força muscular, no ponto de equilíbrio e aumento da pressão arterial. Como cita Boiani et al. (2015)

Todos estes fatores levam os indivíduos a apresentar declínio em sua qualidade de vida e em sua mobilidade, aumentando os riscos de ocorrência de quedas, diminuindo a facilidade de mobilidade e, enfim, apresentando dependência e prejuízo em sua autonomia. Estas limitações impostas pelo processo de envelhecimento levam ao idoso necessitar do auxílio de terceiros, sejam eles cuidadores, enfermeiros ou familiares [...] (BOIANI et al., 2015).

Os dados apontam para a importância do desenvolvimento de dispositivos de tecnologia assistiva, que são dispositivos que contribuem para proporcionar ou ampliar habilidades funcionais de pessoas com deficiência, incapacitadas ou com mobilidade reduzida e consequentemente promover autonomia e inclusão. Para implantação da tecnologia assistiva não se faz necessário muitos recursos, pois qualquer equipamento ou parte dele, produto ou sistema fabricado utilizado para aumentar, manter ou melhorar as capacidades funcionais das pessoas que necessitam de cuidados, já estão compreendidos no conceito.

A tecnologia assistiva é dividida em 11 categorias, em sua respectiva ordem: auxílios para a vida diária; comunicação aumentativa e alternativa; recursos de acessibilidade ao computador; sistemas de controle de ambiente; projetos arquitetônicos para acessibilidade; órteses e próteses; adequação postural; auxílios de mobilidade; auxílios para cegos ou com visão subnormal; auxílios para surdos ou com déficit auditivo; adaptação em veículos. O projeto em questão está classificado em duas delas: a primeira, auxílios para a vida diária, e a oitava, auxílios de mobilidade. A primeira é caracterizada por materiais e produtos para auxílio em tarefas rotineiras, entre elas o banho e executar necessidades. Já a oitava categoria, é definida por produtos que melhorem a mobilidade pessoal.

Realizando uma análise de mercado com auxílio das ferramentas "Mapa Mental" (Buzan, 2006), e "Brainstorming", foram detectadas algumas necessidades, tais como: Conforto, Segurança, Resistência, Empatia e Mobilidade. E a partir desses dados pôde-se desenvolver um mapa mental, apresentado na figura 1, que serviu como norteador preliminar do projeto. 
Figura 1 - Mapa mental

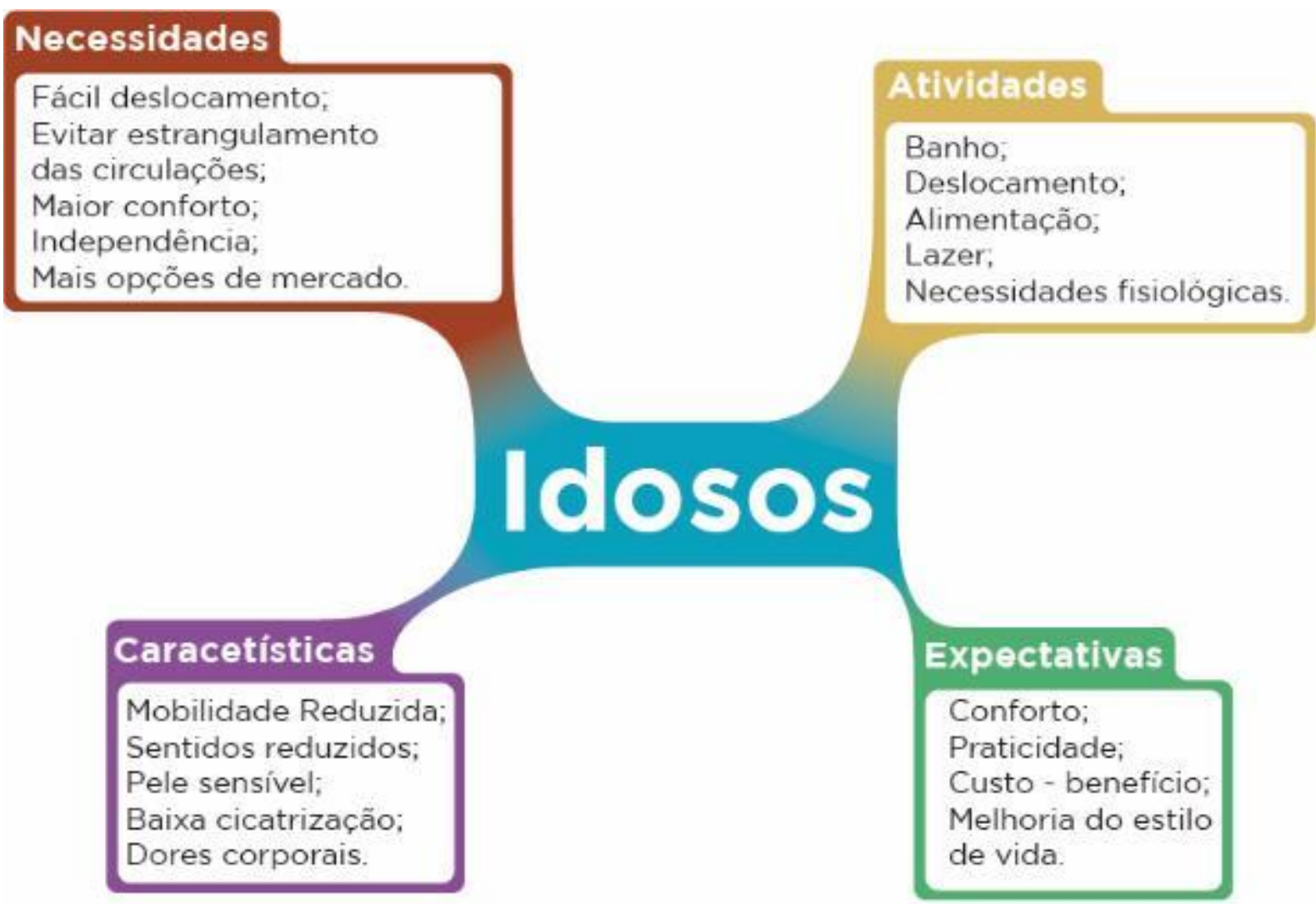

Fonte: Autores (2019)

Com essa perspectiva da população brasileira, um fato importante a se considerar são os acidentes que acontecem com as pessoas idosas, principalmente as quedas, pois com o avançar da idade, o equilíbrio e a força muscular tendem a diminuir. Esses acidentes podem vir a provocar traumatismo craniano, fraturas, contusão muscular e, principalmente, o medo de cair novamente. Tendo em vista esses fatores, observou-se a necessidade de desenvolvimento de um produto que transmita segurança ao usuário, criando assim uma experiência que possa auxiliar a superação de traumas ocasionados por experiências anteriores. Nesse sentido, este trabalho apresenta uma cadeira de rodas para banho, a partir da observação que o banheiro é um dos locais mais utilizados pelos idosos, além de ser um ambiente onde são recorrentes os acidentes domésticos com pessoas idosas. Na figura 2, pode-se observar o Diagrama de Ishikawa no qual são pontuadas as causas para a necessidade identificada. 
Figura 2 - Diagrama de Ishikawa

\title{
Diagrama de Ishikawa
}

Materiais

Fragilidade:

Escassez.
Experiência

Insegurança;

Acidentes.

Acidentes e Danos

a Saúde do Usuário

\author{
Agravamento \\ de problemas. \\ Falta de \\ Conforto;

\section{Ergonomia}

Fonte: Autores (2019)

Através dos dados apresentados no diagrama de Ishikawa, são reveladas as principais causas do déficit no mercado atualmente, os quais estão vinculados com a ergonomia, a experiência do usuário e o material utilizado. Considerando os fatores citados anteriormente, utilizou-se a ferramenta de análise do problema denominada " 5 porquês" (fig.3), proposta por Baxter (2000), para um direcionamento sobre as causas básicas do problema e alternativas que apontam para a criação de um novo produto. 


\section{Cinco Porquês}

\section{Melhorar o Produto Existente}

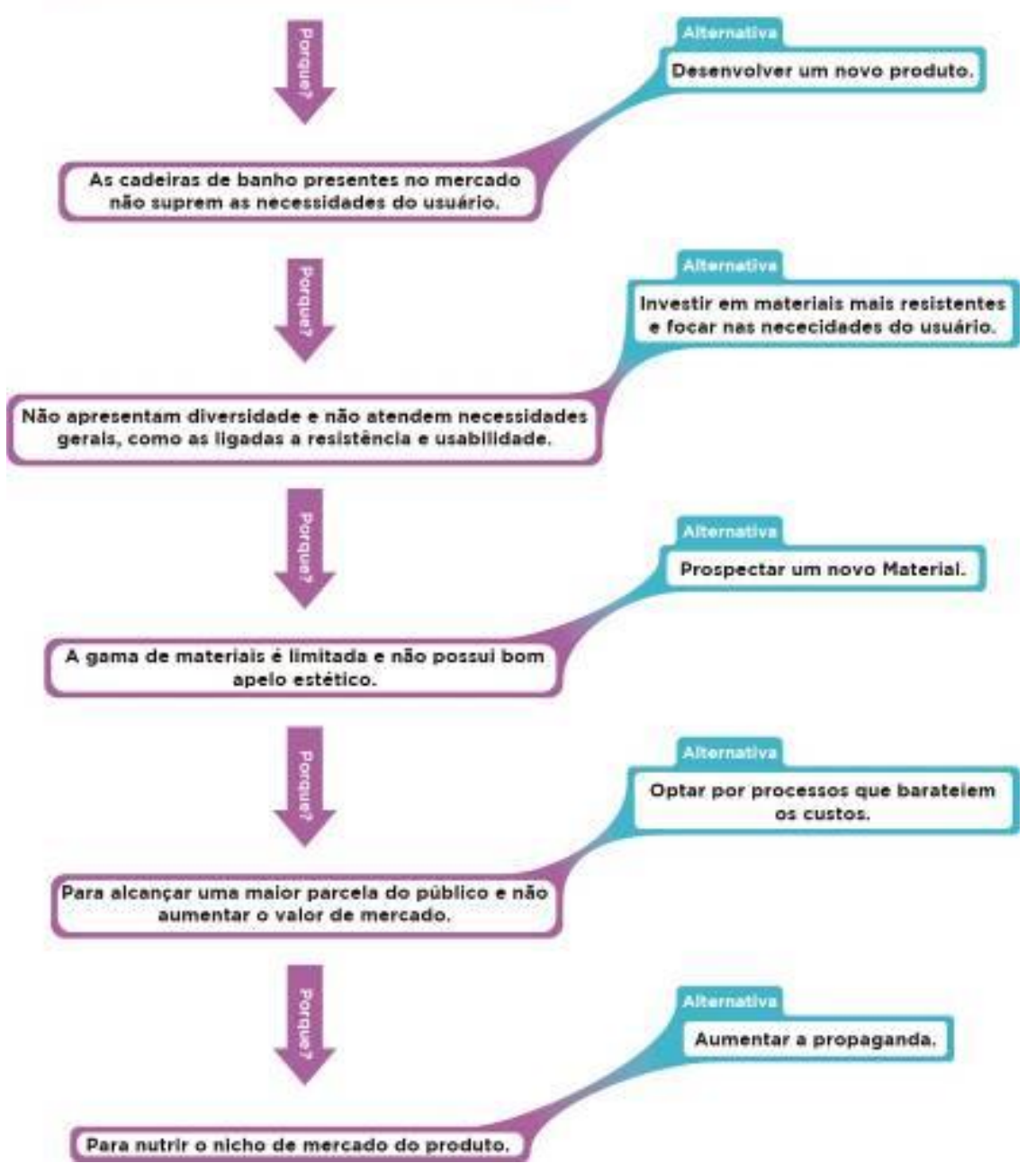

Fonte: Autores (2019)

Por meio dos resultados obtidos na análise do problema, pode-se afirmar que se faz necessário o desenvolvimento de um novo produto que atenda às necessidades do usuário e que seja constituído por um material mais resistente. Portanto, para o desenvolvimento do produto é necessário pensar em todos esses aspectos e assim atender a demanda do mercado. Deste modo, o objetivo principal é desenvolver uma cadeira de banho para o auxílio de idosos com mobilidade reduzida que potencialize a independência do usuário e, consequentemente, diversificar o mercado de cadeiras de banho para pessoas com mobilidade reduzida. 


\section{Metodologia}

A metodologia utilizada no desenvolvimento desse projeto é hibrida, embasada principalmente na proposta por Baxter (2000), por suprir de forma eficiente as principais necessidades do desenvolvimento do projeto. Foram também utilizadas ferramentas projetuais propostas por outros autores como Bonsiepe (1984) e Vianna (2012). O processo metodológico proposto se deu através de cinco etapas: a) planejamento do produto; b) desenvolvimento conceitual do produto; c) configuração do projeto; d) desenvolvimento da ideia escolhida e e) definições de produção industrial.

O planejamento do produto se trata da etapa inicial, e nesta, são feitas as definições básicas como oportunidades de mercado e necessidades do usuário. Também é crucial uma análise criteriosa do mercado existente, tanto sobre os produtos oferecidos quanto dos consumidores, a fim de reduzir os riscos de projeto. A segunda etapa se trata do desenvolvimento conceitual do produto, na qual são gerados conceitos para o projeto. Para esta, Baxter (2000) propõe diversas ferramentas para o estímulo criativo, como o Brainstorming. A partir deste ponto, foram gerados conceitos que foram analisados durante a terceira fase: configuração do projeto. Nesta etapa os conceitos são utilizados para geração de ideias, e neste ponto, Baxter salienta que não deve haver limitações, e todos os aspectos do produto devem ser analisados, e se necessário, revisitados em etapas anteriores. $\mathrm{O}$ autor também propõe a utilização de ferramentas como a Análise das Forças, Oportunidades, Fraquezas e Ameaças (FOFA) e Análise de concorrentes para auxiliar durante a definição da ideia. A quarta etapa consiste no desenvolvimento da ideia escolhida, nesta, são definidos os aspectos estruturais, construtivos e funcionais do produto. $\mathrm{O}$ autor também recomenda a prototipação do produto para a execução de testes físicos e perceptivos, com o intuito de analisar uma experiência de uso, e por fim, a última etapa, na qual são realizadas as definições de produção industrial. Para tanto, o autor supracitado recomenda a confecção de um protótipo de produção, no qual são feitas todas as análises do protótipo anterior, caso aprovado, o projeto é concluído.

\section{Levantamento de dados}

A partir da observação de produtos similares no mercado e dispondo do auxílio de algumas ferramentas para coletar as informações necessárias foi estabelecido um suporte para o desenvolvimento do produto, aliado a dados referente a análise do público alvo. O detalhamento desta análise pode ser conferido nos tópicos que seguem. 


\subsection{Análise de mercado}

Para Análise de mercado foram utilizadas duas ferramentas: a matriz de forças, fraquezas, oportunidades e ameaças (FOFA), proposta por Baxter (2000), e a análise de custo-benefício. FOFA é uma ferramenta através da qual é realizada uma análise de fatores, com o intuito de entender o nicho de mercado onde o produto a ser desenvolvido está inserido e assim, criar uma base de informações necessárias. Na figura 4, pode-se analisar a matriz desenvolvida de acordo com as informações coletadas sobre o mercado de cadeiras higiênicas.

Figura 4 - FOFA

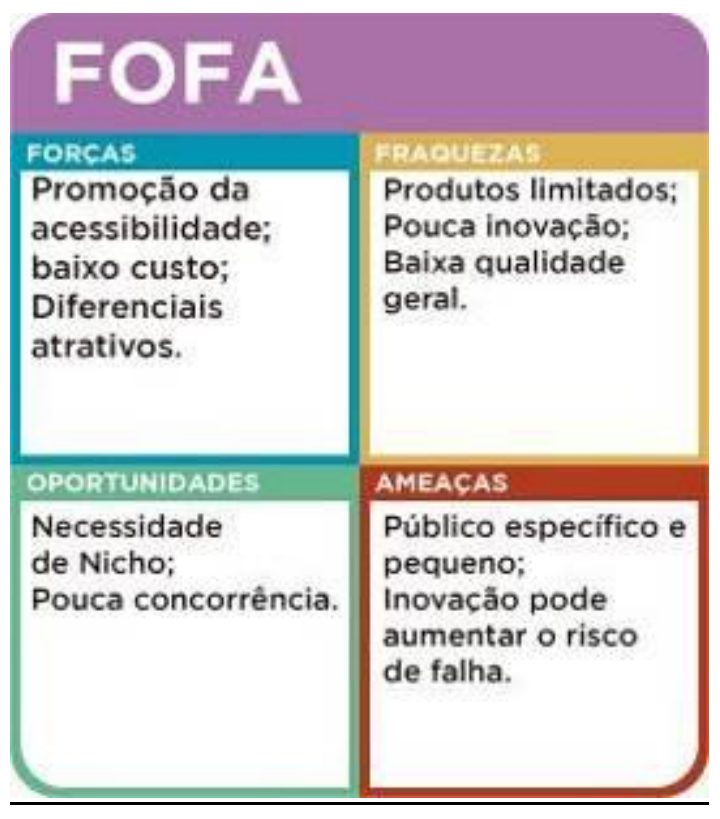

Fonte: Autores (2019)

Através da matriz FOFA, foi possível entender melhor a carência existente no mercado pois observa-se que as fraquezas e ameaças estão atreladas entre si, no quesito sobre inovação de produtos e materiais, além de ressaltar especificidades do público. Para complementar, com análise de custo-benefício (fig.5) foi possível estabelecer e ilustrar o quanto de qualidade, de forma geral, um produto oferece por determinado valor. No gráfico, cada produto é posicionado de forma comparativa, visando demonstrar qual produto é mais atraente para o público. 


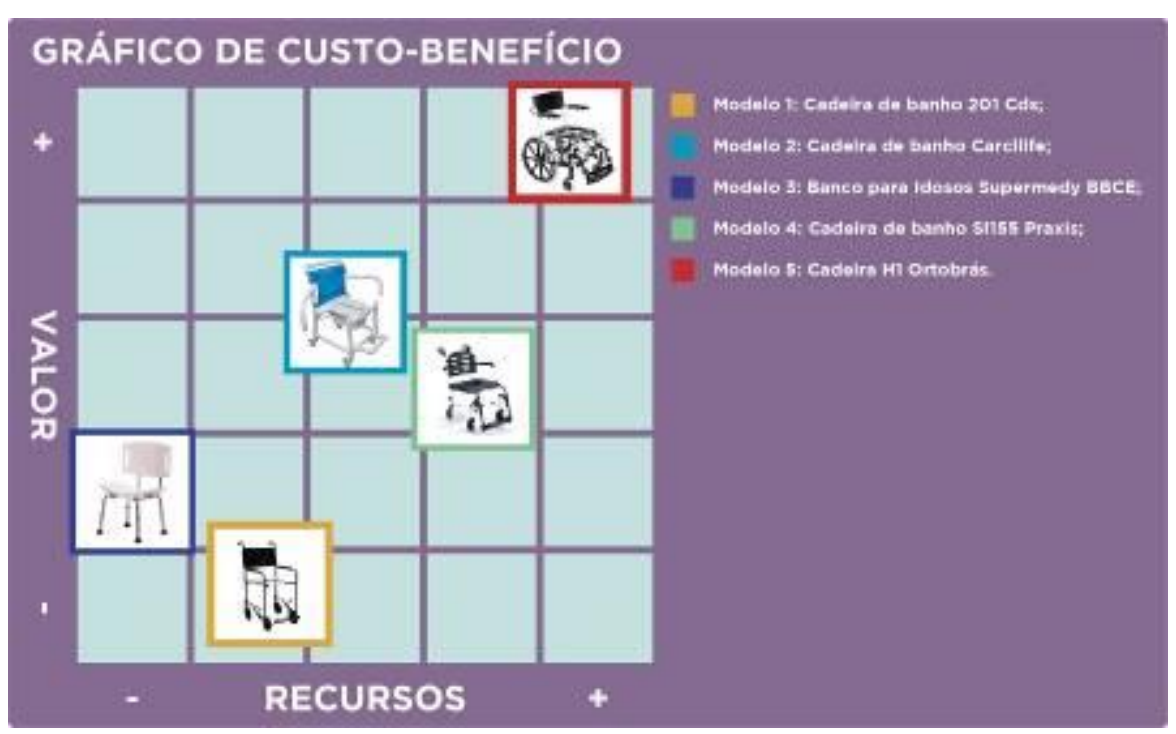

Fonte: Autores (2019)

Com a análise apresentada anteriormente, pôde-se obter uma noção de mercado na qual foi criado um parâmetro a ser trabalhado, pois pode-se perceber que a cadeira com mais atributos é a cadeira mais cara em relação às outras apresentadas. Consequentemente, essas informações serão usadas como diretrizes durante o desenvolvimento, sendo elas em relação a custo, atributos e materiais.

\subsection{Análise do público}

A análise do público se deu através da criação de personas, que são representações do cliente ideal. Para se ter melhor embasamento na criação, foram entrevistados usuários reais para entender o contexto do seu cotidiano. As personas apresentadas abaixo sintetizam os resultados obtidos (fig. 6 e 7). 
[Figura 6 - Persona 1

\begin{tabular}{|l|l|}
\hline \multicolumn{1}{|c|}{ Idade: 65 anos } \\
\hline
\end{tabular}

Fonte: Autores (2019)

Figura 7 - Personas 2, 3 e 4

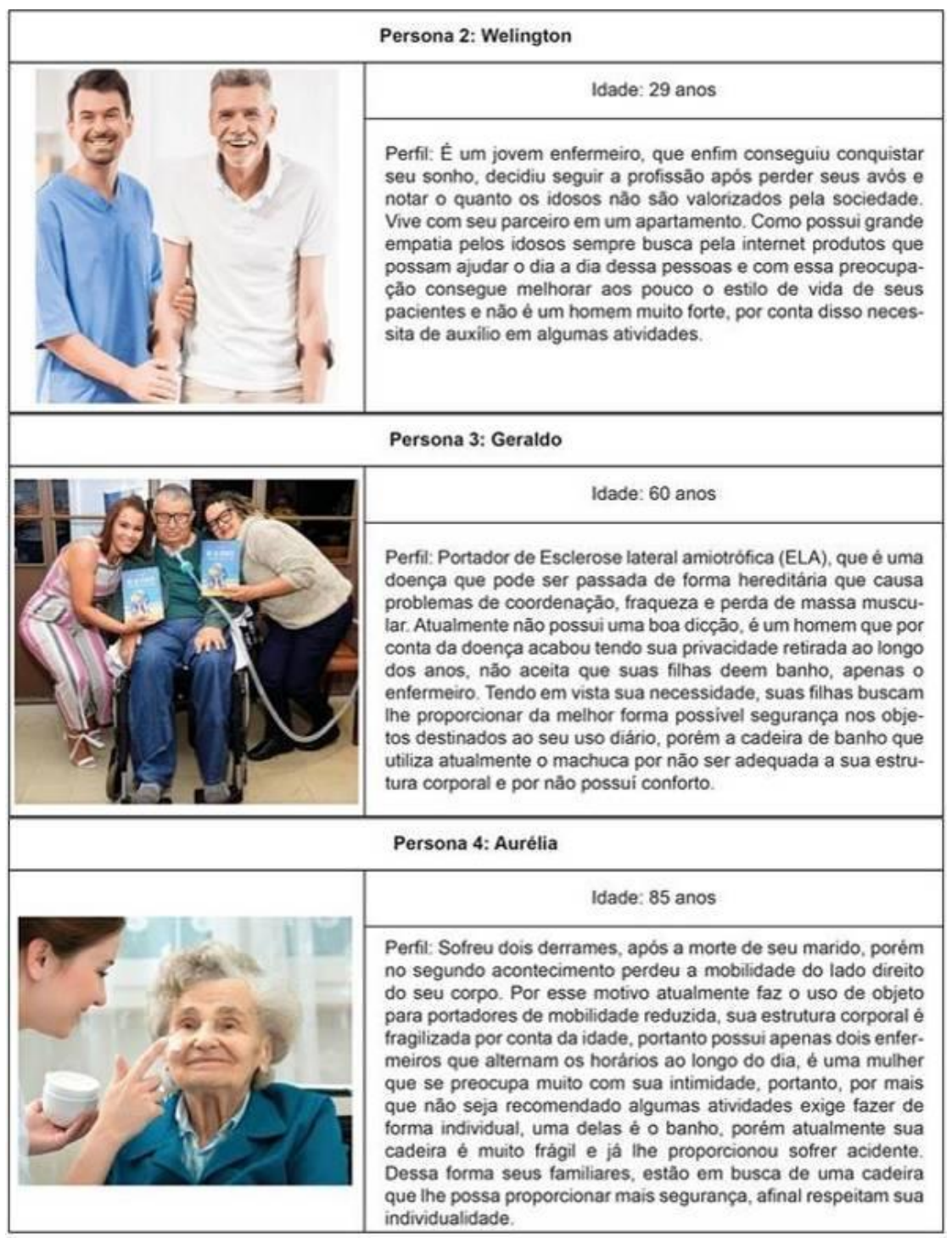

Fonte: Autores (2019). 
Através das personas foi possível entender mais sobre o público alvo, e como a partir dos dados levantados foi desenvolvido o mapa de empatia. O Mapa da Empatia (fig.8) é uma ferramenta utilizada para sintetizar as informações obtidas nas entrevistas e assim ter uma melhor compreensão e experiência de imersão.

Figura 8 - Mapa de empatia

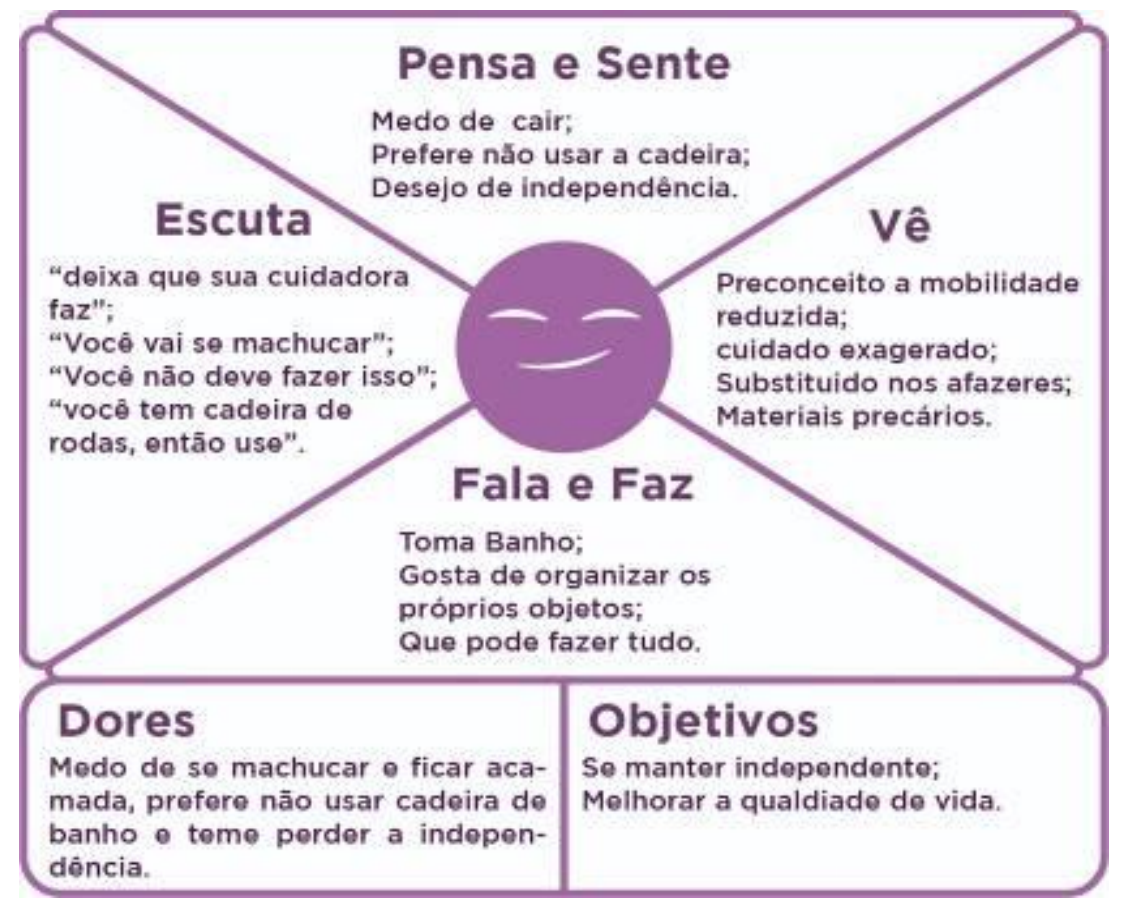

Fonte: Autores (2019)

A triagem de informações realizada através do mapa de empatia e o processo de imersão feita no cotidiano do usuário permitiu que algumas questões fossem trabalhadas para uma melhor experiência do usuário, em como o produto irá auxiliar em sua rotina diária.

\subsection{Análise estrutural e análise funcional}

Essa etapa se caracteriza pela análise dos componentes que formam a estrutura do produto e suas funções. Com os resultados pôde-se perceber e entender os mecanismos do produto e quais os materiais disponíveis no mercado. No mercado, existem basicamente três tipos de cadeiras de banho: a com rodas, com rodízios e com pés e para a análise estrutural, utilizou-se um produto similar ao que está sendo desenvolvido, o produto de referência é a Cadeira de Banho com Rodas - CM5176 da marca WOG. 
Já para a análise funcional, foram estabelecidos três aspectos de cada parte do produto, a função principal, a função secundária e os materiais utilizados (fig. 9).

Figura 9 - Análise estrutural e funcional

\section{Análise Estrutural e Funcional

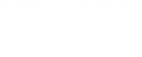

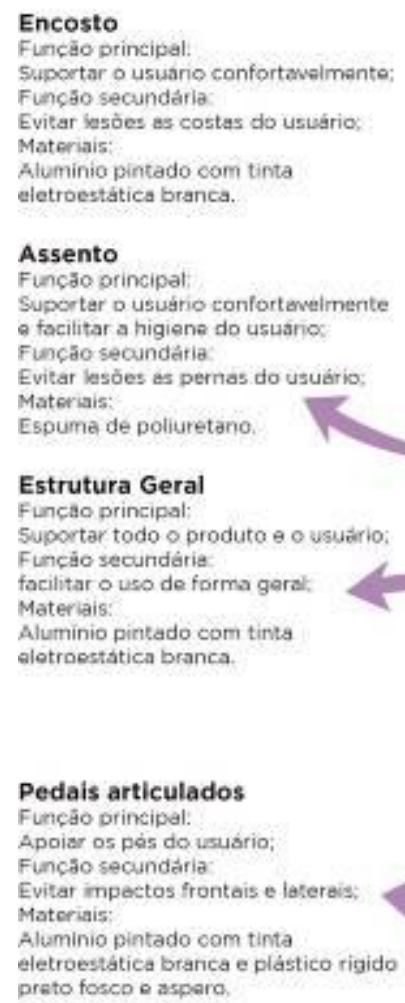

Pedais articulados Funçäo principal: Apoiar os pós do usuário; Funço secundária:

Evitar impectos frontais e laterais; Matoriais:

Aluminio pintado com tinta

eletroestática branca e plástico rigido

preto fosco e asparo.

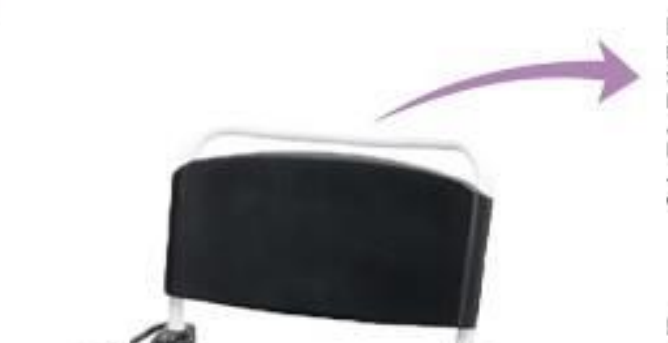

BARRA DE APOIO

Funcso principal:

Sustentacâo do encosto:

Funçăo secundária:

Apoio para mobilidado:

Aluminis pintado com tinta

eletroestatica branca.

Descansos para braço articulaveis Funça principal:

Apoier os braços confortavelmente.

Funcso secundária:

Evitar lesoes as costas do usuario:

Moteriais:

Aluminio pintado com tinta eletronstática branca e espuma de poliuretano.

Coletor

Funcaso principal:

coletar dejetos e facilitar a higiene do

usuario:

Funça secundaria.

facilitar a limpeza do produto,

Materiais:

Plastice rígido preto polido

\section{Rodizios}

Funcalo principal:

Suportar a estrutura geral solore o cháx Funçăo secundária:

Maver o objeto facilmente:

Materiais: Plastico rígido preto e borrache armote-
cedora.

Fonte: Autores (2019)

A partir das análises realizadas, foi estabelecida uma base para definir os requisitos e os parâmetros do projeto, e, através delas, foi possível entender a funcionalidade de cada componente e o que é indispensável para uma cadeira de banho, assimilando o que seria relevante acrescentar no projeto a ser desenvolvido.

\subsection{Análise ergonômica}

Essa análise se dá através do uso de duas ferramentas: a jornada do usuário e a análise de usabilidade. A jornada do usuário é uma ferramenta, proposta pelo Design Thinking, na qual descreve as etapas de interação entre o usuário e o produto ou serviço em questão. Já a análise de usabilidade é uma ferramenta que mostra como usuário se comporta com produto. 


\subsubsection{Jornada do usuário}

Ao encontrar-se com mobilidade reduzida, o indivíduo acaba tendo algumas necessidades além do normal, como o auxílio durante a alimentação, no deslocamento, na utilização de cadeira de rodas, cadeira de banho e cadeira de rodas automatizada para passeio. Dessa forma, o usuário ou o responsável por ele, realiza a pesquisa de mercado em busca de objetos, podendo ser realizada por meio da internet ou em lojas físicas, em seguida, a escolha na hora compra do objeto é feita ao identificar o produto mais adequado para a necessidade, do valor acessível e entre outros quesitos. Após a realização da compra, o produto é testado com relação ao conforto do produto na interação com o usuário, sendo necessário o deslocamento ao local onde se encontra a cadeira. Neste processo, é observada a usabilidade e resistência do produto.

\subsubsection{Usabilidade}

O teste de usabilidade tem a finalidade observar funcionalidade do produto e como o usuário se adapta ao mesmo. Para o teste de usabilidade, utilizou-se como base o mesmo produto analisado anteriormente, a Cadeira de Banho com Rodas - CM5176 da WOG (fig. 10).

Figura 10 - Análise de usabilidade

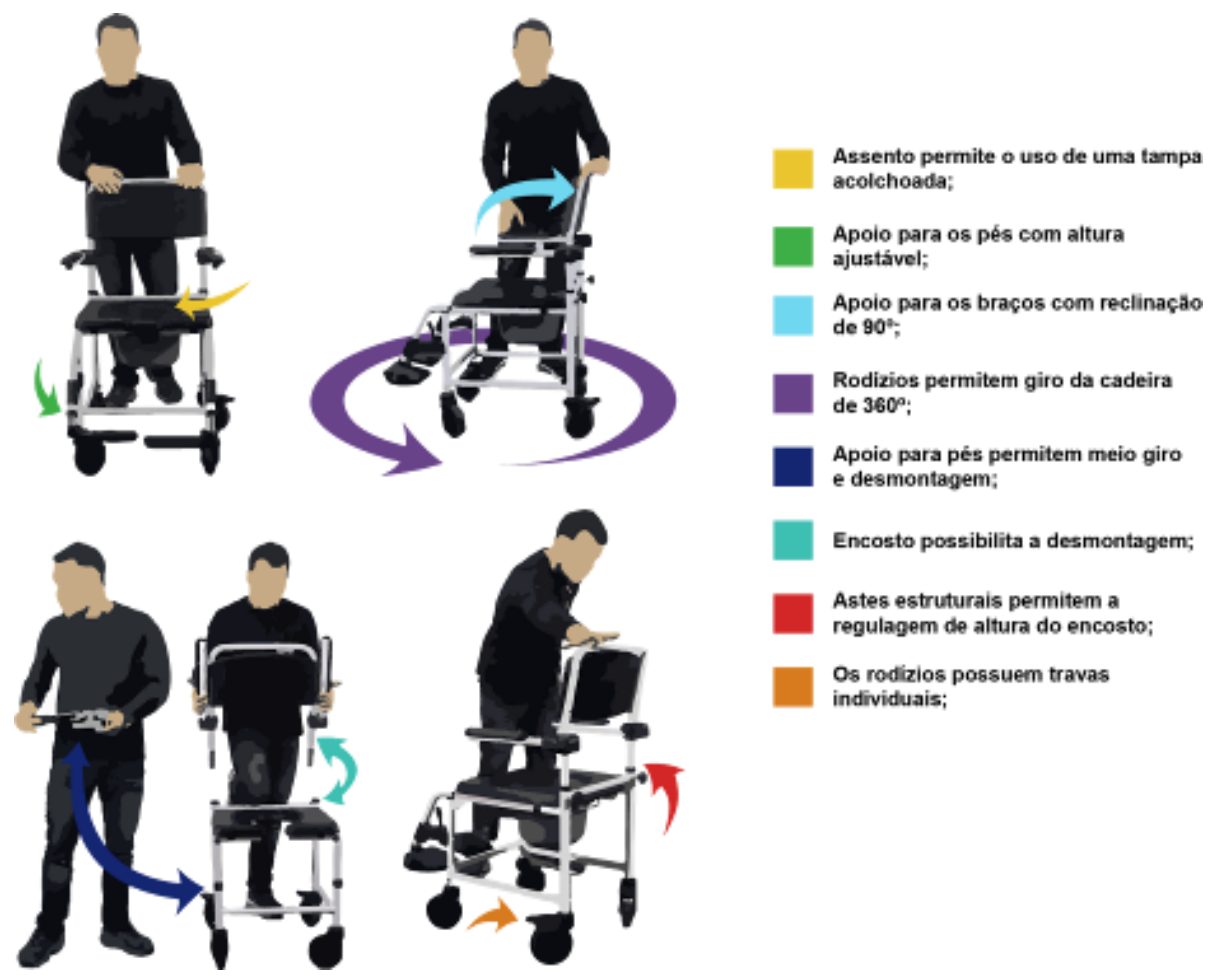

Fonte: Autores (2020) 


\subsection{Análise de materiais}

É uma análise voltada para identificar os materiais encontrados em produtos disponíveis no mercado e suas características, para então observar quais seriam mais adequados ao projeto (fig. 11).

Figura 11 - Materiais

\begin{tabular}{|c|c|}
\hline Material & Descrição \\
\hline Polietileno & $\begin{array}{l}\text { O Polietileno (PE) é um termoplástico, plástico que se deforma com o calor, pode ser } \\
\text { encontrado em cinco diferentes variaçöes, que são: Polietileno de alta densidade (PEAD), } \\
\text { Polietileno de baixa densidade (PEBD), Polietileno linear de baixa densidade (PELBD), } \\
\text { Polietileno de ultra alto peso molecular (PEUAPM) e Polietileno de ultra baixa densidade } \\
\text { (PEUBD), todos podem ser reciclados e comercializados como material recuperado. O } \\
\text { polietileno pode ser encontrado no encosto e no assento de determinadas cadeiras de } \\
\text { banho, e em suas variadas formas possui propriedades únicas, tais como resistência ao } \\
\text { impacto, alta flexibilidade, e boa estabilidade térmica e química, em determinadas condi- } \\
\text { ções. Almofadado é o nome dado a certos tipos de assentos sanitários que são a base } \\
\text { de polietileno expandido e superficie flexivel. }\end{array}$ \\
\hline Alumínio & $\begin{array}{l}\text { O alumínio é um metal leve, macio, porém resistente, de aspecto metálico branco, que } \\
\text { tem um revestimento fino de um óxido. O alumínio tem inúmeras características contudo } \\
\text { vale ressaltar que ele é um material que pode ser infinitamente reciclável, pois não perde } \\
\text { suas propriedades físico-químicas, apresenta baixo peso combinado com resistência } \\
\text { mecânica e alta resistência à corrosão. Frequentemente utilizado nas peças estruturais da } \\
\text { cadeiras de banho. }\end{array}$ \\
\hline Aço Carbono & $\begin{array}{l}\text { O Aço Carbono é resultado da combinação de dois elementos: ferro e carbono. Suas } \\
\text { propriedades mecânicas variam conforme o tipo de aço carbono e seus composições, } \\
\text { como manganês, silicio e o fósforo. O aço carbono possui um custo acessivel, oferecendo } \\
\text { diversos tipos de aplicações e de resistências. Geralmente empregado na estrutura das } \\
\text { cadeiras de banho, se apresenta de três maneiras diferentes que são classificadas de } \\
\text { acordo com a quantidade de carbono e podem ser : baixo carbono, médio carbono e alto } \\
\text { carbono. }\end{array}$ \\
\hline $\begin{array}{l}\text { Poliuretano } \\
\text { Injetado }\end{array}$ & $\begin{array}{l}\text { O Poliuretano é um polimero aplicado na fabricação de espumas rígidas ou flexíveis e, } \\
\text { portanto, extremamente versátil para uma diversidade de aplicações na indústria.O poliu- } \\
\text { retano injetável é aquele que, como o próprio nome já adianta, é injetado em um local, é } \\
\text { geraimente utilizado nos assentos das cadeiras higiênicas. }\end{array}$ \\
\hline Nylon & $\begin{array}{l}\text { O nylon, no português náilon, é uma fibra têxtil sintetizada em laboratório, faz parte da } \\
\text { classe dos polímeros. A fibra orgânica nylon possuí uma vasta utilização, é uma fibra leve, } \\
\text { resistente e que não retém sujeira. Sua capacidade de absorção é muito baixa, o que } \\
\text { permite que seque facilmente e é de fácil limpeza. }\end{array}$ \\
\hline Poliéster & $\begin{array}{l}\text { Poliéster é uma categoria de polímeros que contém um grupo funcional éster na cadeia } \\
\text { principal. A maioria dos tipos de poliéster são termoplásticos e possuem diversas aplica- } \\
\text { ções. O poliéster pode ser encontrado no assento e no encosto de cadeira de banho, em } \\
\text { alguns casos de formas distintas. O poliéster é um material de alta durabilidade, de fácil } \\
\text { higienização e com grande resistência. É utilizado também o tecido poliester em alguns } \\
\text { encostos, porém os tecidos com fibras sintéticas, que é o caso do poliéster e do nylon, } \\
\text { citado anteriormente, tem como pontos negativos : a facilidade de dar bolinha por causa } \\
\text { do atrito, de serem mais frágeis a movimentos bruscos e calor. }\end{array}$ \\
\hline
\end{tabular}


Através dessa análise, pôde-se identificar que os melhores materiais, os quais se encaixam nos requisitos estabelecidos, foram o alumínio e poliuretano injetado.

\subsection{Projeto conceitual}

De acordo com Baxter (2000), o projeto conceitual tem o objetivo de produzir princípios de projeto para o novo produto, e para tanto, foram utilizados os painéis imagéticos. Os três painéis imagéticos apresentados a seguir são os painéis de: estilo de vida, expressão do produto e o tema visual. O painel de estilo de vida (fig.12), retrata a experiência do usuário, buscando transmitir boas sensações e boas recordações, ao proporcionar independência ao usuário.

Figura 12 - Painel de estilo de vida

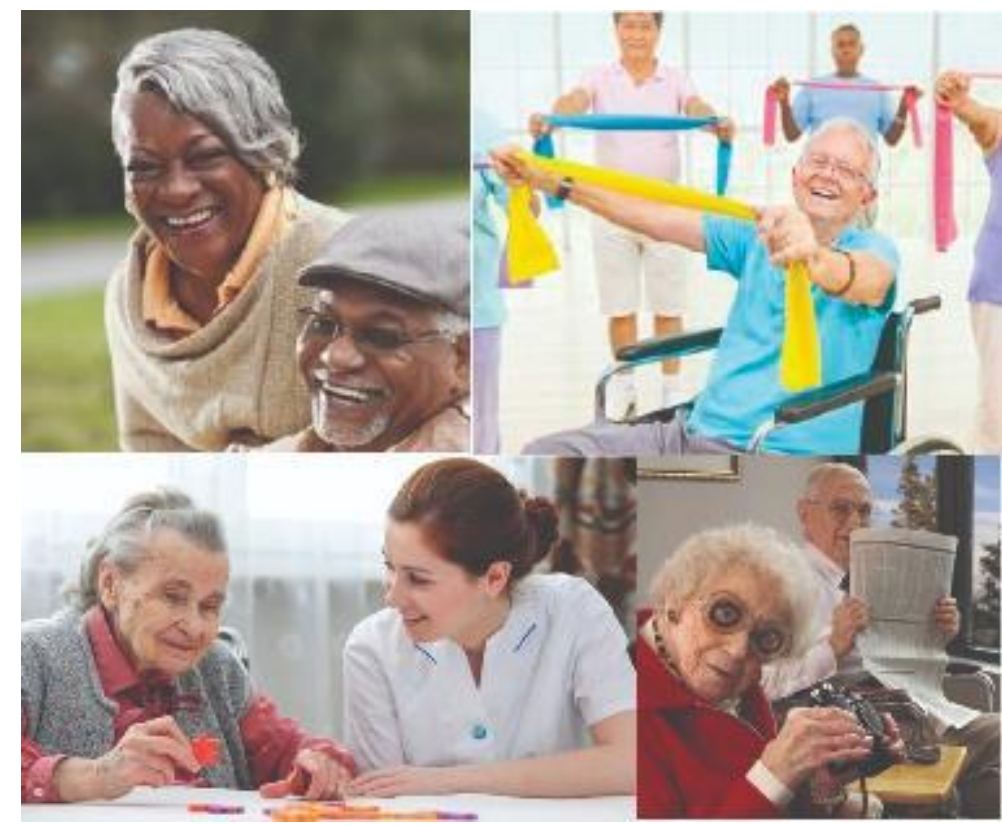

Fonte: Autores (2019)

O painel de expressão do produto (fig.13) retrata as sensações proporcionadas ao usuário, que neste caso retrata segurança, independência, conforto e equilíbrio. 
Figura 13 - Painel de expressão do produto

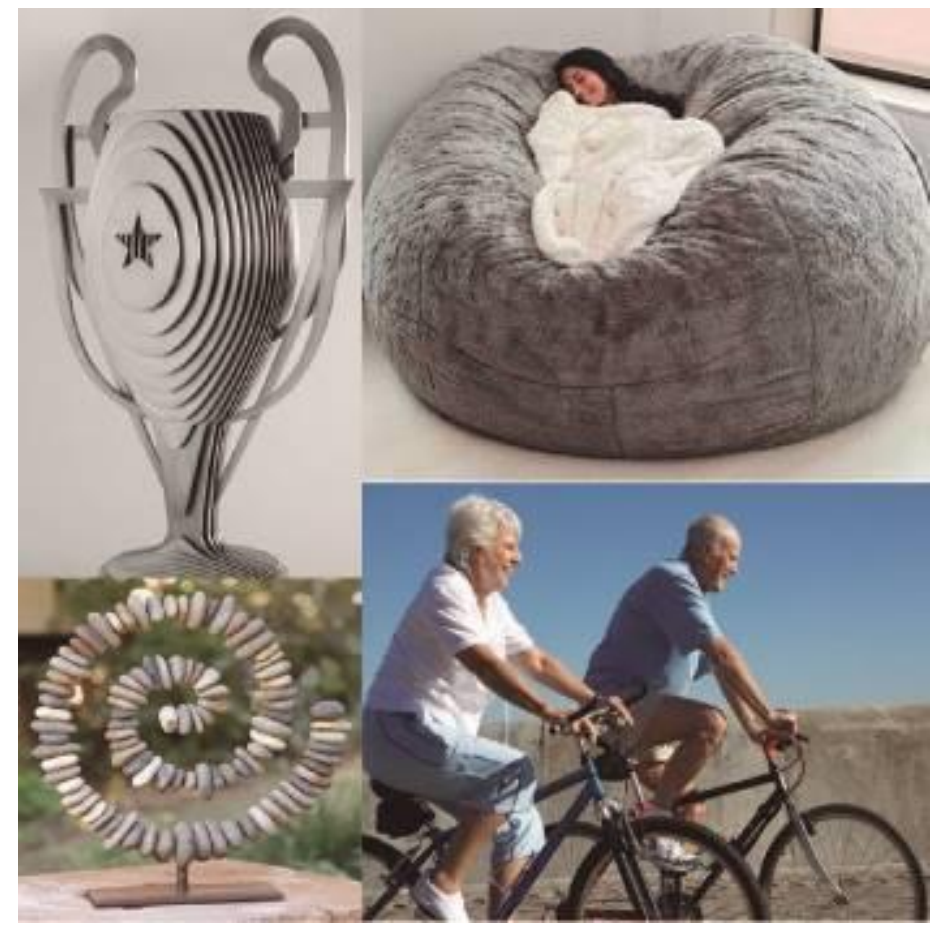

Fonte: Autores (2019)

Já o painel de tema visual (fig.14) retrata a estética do produto, seu apelo visual. O painel a seguir expressa um design clean focando funcionalidade do produto, com um caráter minimalista e monocromático.

Figura 14 - Painel de tema visual

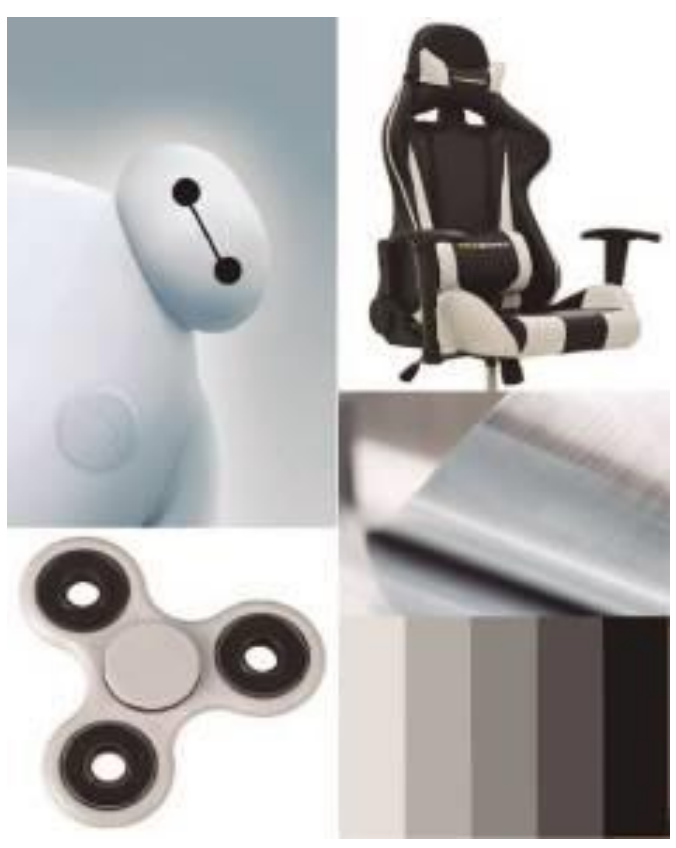

Fonte: Autores (2019) 
Como resultado obtido nesta etapa, pôde-se definir que o conceito do projeto está atrelado as sensações despertadas no usuário, como conforto e segurança.

\section{Requisitos e parâmetros}

Os requisitos e parâmetros são os resultados das análises feitas no decorrer do projeto. Os requisitos são os fatores necessários, já os parâmetros aspectos quali-quantitavos que os requisitos precisam ter.

\subsection{Matriz GUT}

A Matriz de Priorização de GUT (Gravidade x Urgência x Tendência) é uma ferramenta empregada na hierarquização de problemas, utilizada para definir de forma racional as ações a serem tomadas tendo em vista a gravidade, a urgência e a tendência do ocorrido. Os problemas são avaliados e pontuados de 1 a 5 , sendo os problemas encontrados o resultado de uma pesquisa desk sobre as queixas frequentemente encontradas (fig. 15).

Figura 15 - Matriz GUT

\begin{tabular}{|c|c|c|c|c|}
\hline PROBLEMAS & GRAVIDADE & URGÊNCIA & TENDÊNCIA & G x U x T \\
\hline A & 5 & 3 & 3 & 45 \\
\hline B & 4 & 4 & 2 & 32 \\
\hline C & 5 & 5 & 4 & 100 \\
\hline D & 5 & 4 & 1 & 20 \\
\hline $\begin{array}{l}\text { A: Rodas travando; B: Material frági; C: Instabilidade/Sustentação comprometida; } \\
\text { D: Problemas com tamanho do produto }\end{array}$
\end{tabular}

Fonte: Autores (2019)

Com os resultados obtidos, o índice de problemas a serem resolvidos foi $\mathrm{C}>\mathrm{A}>\mathrm{B}>\mathrm{D}$, sendo $\mathrm{o}$ problema de instabilidade o que possuía maior pontuação.

\section{Geração de alternativas}

É a etapa para geração de soluções para os problemas encontrados, se baseando nos requisitos e parâmetros. Nesta fase toda ideia é bem-vinda, não se restringindo. A seguir, o detalhamento desta etapa. 


\subsection{Analogias}

A ferramenta utilizada no processo criativo foi a denominada "Analogias". Segundo Baxter (2000), “Analogia é uma forma de raciocínio, em que as propriedades de um objeto são transferidas para um outro objeto diferente, mas com certas propriedades em comum". Para a criação das analogias foram utilizados como inspiração três objetos: o fidget spinner (brinquedo giratório voltado para crianças e adolescentes), por ter um formato mais orgânico e ergonômico (fig. 16); o Baymax, personagem da Disney que é um robô programando para zelar a saúde de seu usuário (fig. 17); e por fim, uma cadeira gamer, que simboliza o conforto oferecido por essas cadeiras. Abaixo as alternativas geradas (fig. 18):

Figura 16 - Alternativa 1

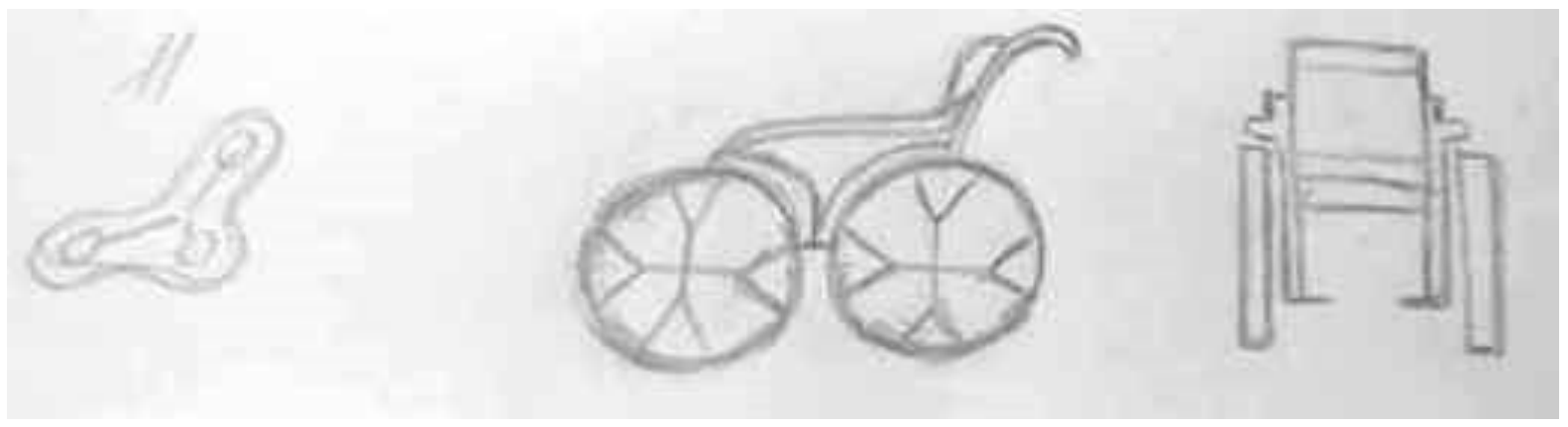

Fonte: Autores (2020)

Figura 17 - Alternativa 2

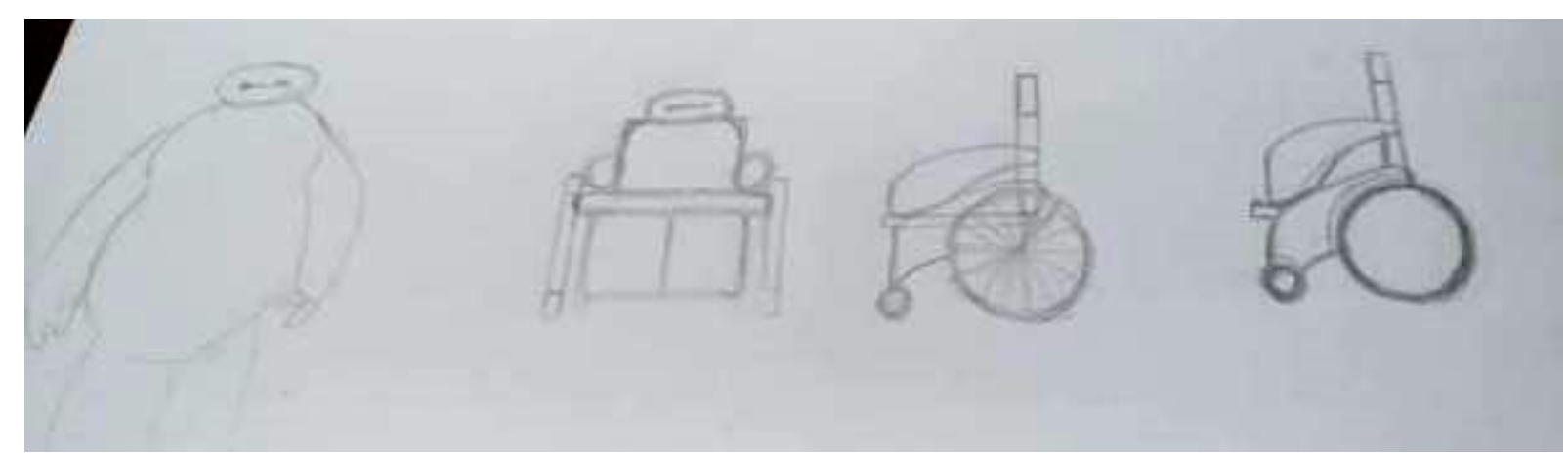

Fonte: Autores (2020) 
Figura 18 - Alternativa 3

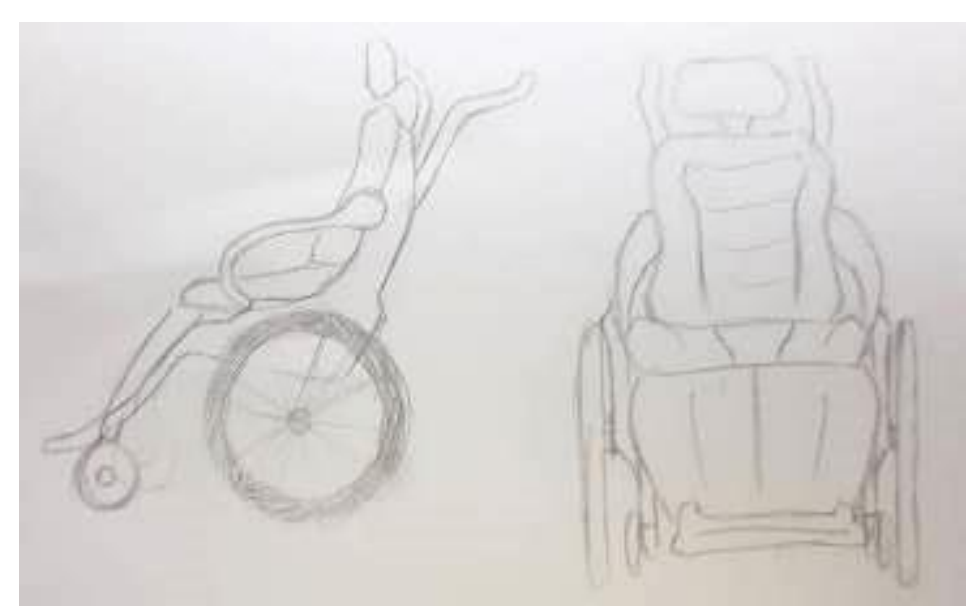

Fonte: Autores (2020)

Para auxiliar na escolha da alternativa, a ferramenta utilizada foi a matriz de posicionamento. De acordo com Vianna (2012), é uma "ferramenta de análise estratégica das ideias geradas, utilizada na validação destas em relação aos critérios norteadores". A matriz de posicionamento é utilizada para validar as ideias criadas utilizando os critérios norteadores para enfim selecionar a alternativa mais benéfica (fig. 19). Os critérios norteadores desse projeto são: o conceito do projeto, o tamanho do objeto, a mobilidade e o dimensionamento. Para cada critério foi designado um peso de acordo com os resultados da matriz GUT.

Figura 19 - Matriz de Posicionamento

Matriz de Posicionamento

\begin{tabular}{|c|c|c|c|c|c|}
\hline & CRITÉRIOS & ALTERNATIVA 1 & ALTERNATIVA 2 & ALTERNATIVA 3 & PESO \\
\hline \multirow{4}{*}{ 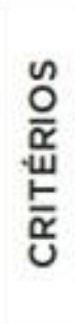 } & A & $\mathrm{x}$ & 2 & $\mathrm{X}$ & 2 \\
\hline & B & $\mathrm{x}$ & 1 & 1 & 1 \\
\hline & C & 4 & 4 & 4 & 4 \\
\hline & D & $\mathrm{X}$ & 3 & 3 & 3 \\
\hline
\end{tabular}

Fonte: Autores (2019) 
Como resultado obtido, a alternativa 2 foi a selecionada, e a partir disso, foi iniciado o detalhamento da alternativa, com o dimensionamento e a prototipagem.

\section{Resultados}

A alternativa 2 foi inspirada no personagem Baymax do filme Big Hero 6, da Walt Disney, no qual Baymax é um robô de saúde, criado para ser uma enfermeira fornecedora de saúde afim de ajudar as pessoas. Suas formas foram utilizadas como referência através da ferramenta de analogias. O conceito do personagem e do projeto se atrela quando eles focam, de certo modo, com o bem-estar do usuário e em sua experiência. Na figura abaixo (fig. 20), se encontram as medidas principais do objeto. O material escolhido para constituir o objeto é o alumínio e o poliuretano injetável.

Figura 20 - Dimensionamento geral do objeto
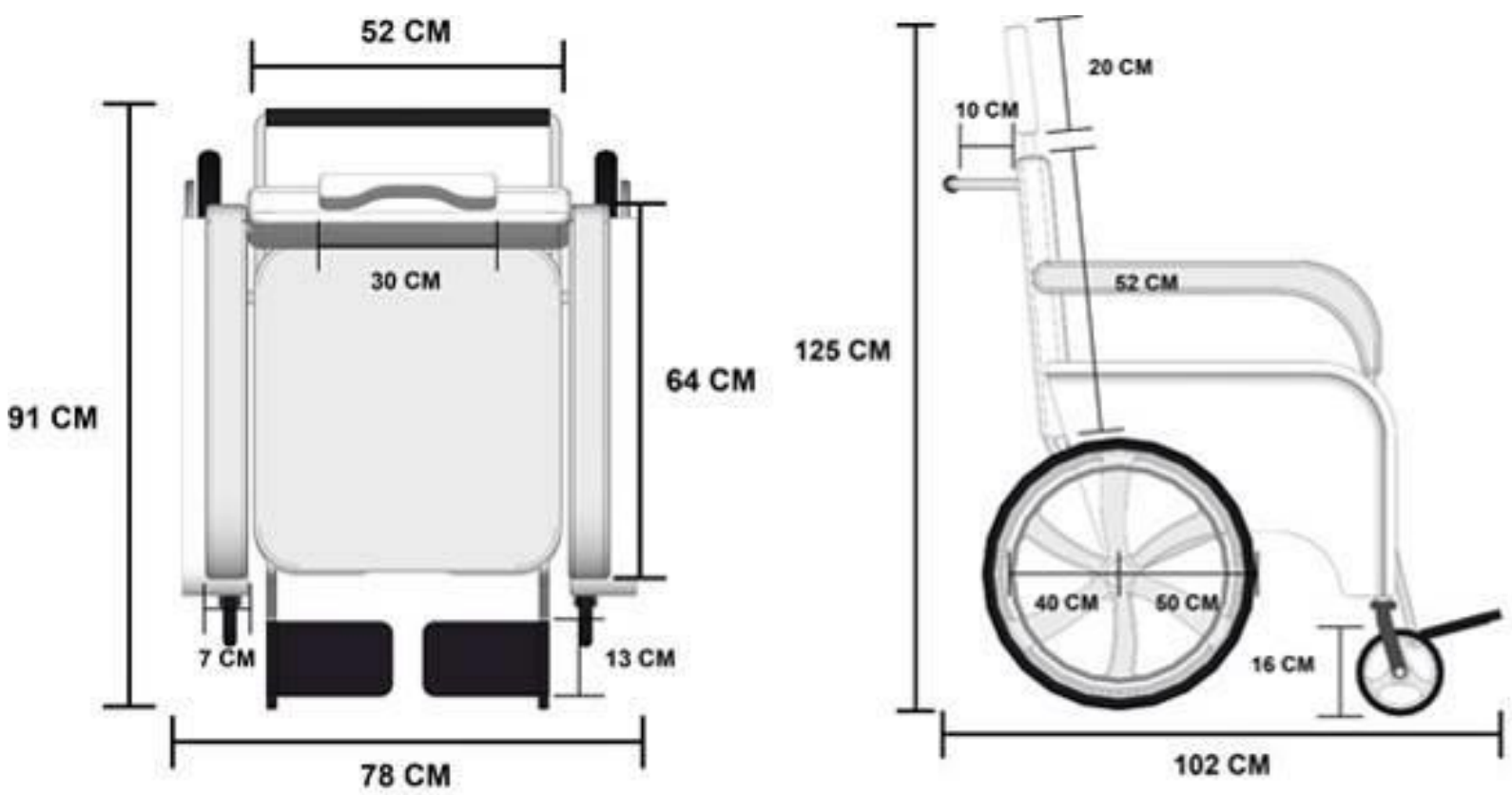

Fonte: Autores (2020)

A partir dessas informações coletadas, foi desenvolvida uma modelagem tridimensional (fig. 21) e o mockup do produto (fig. 22). 
Figura 21 - Modelagem Tridimensional
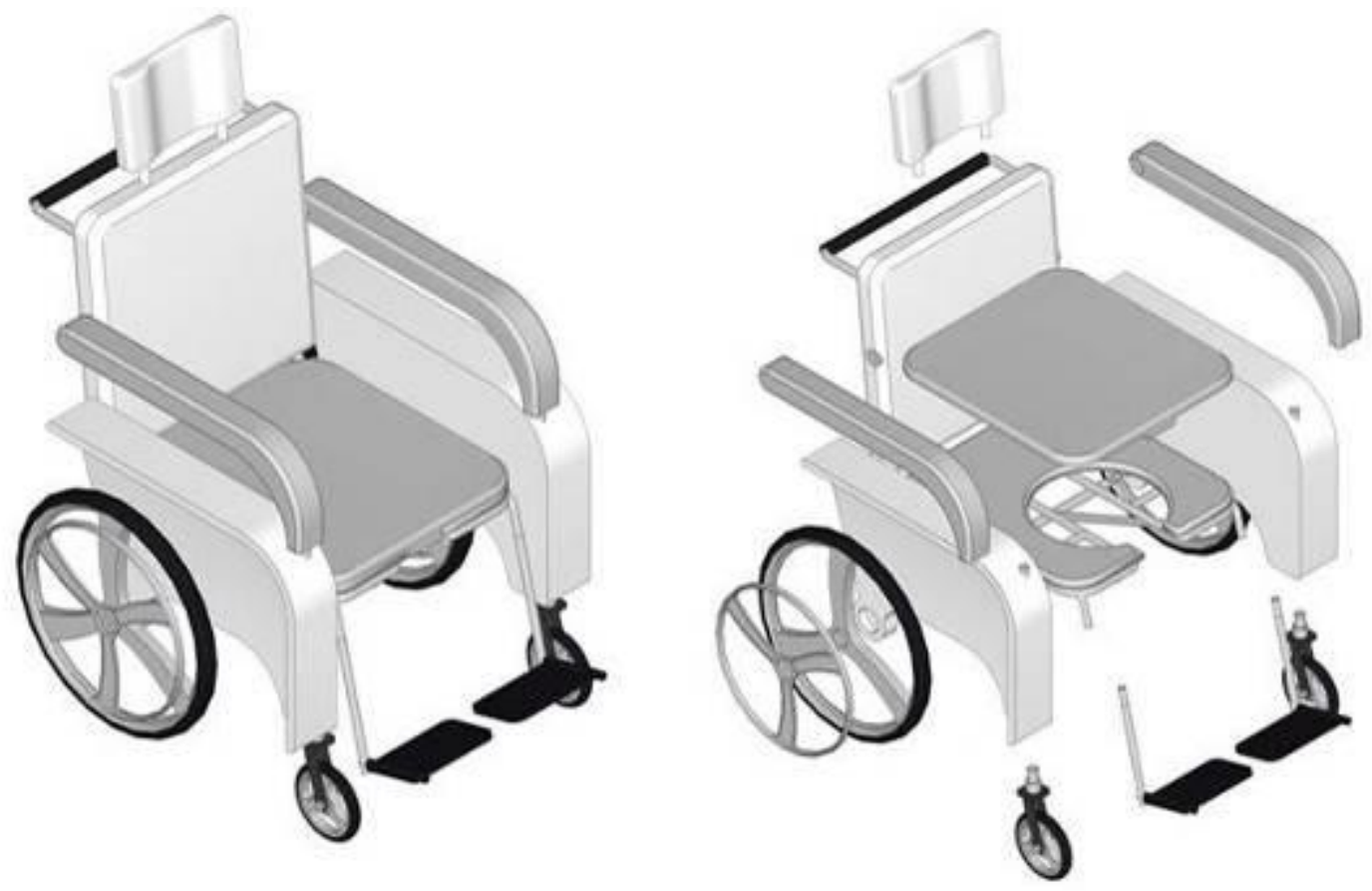

Fonte: Autores (2020)

Figura 22 - Mockup

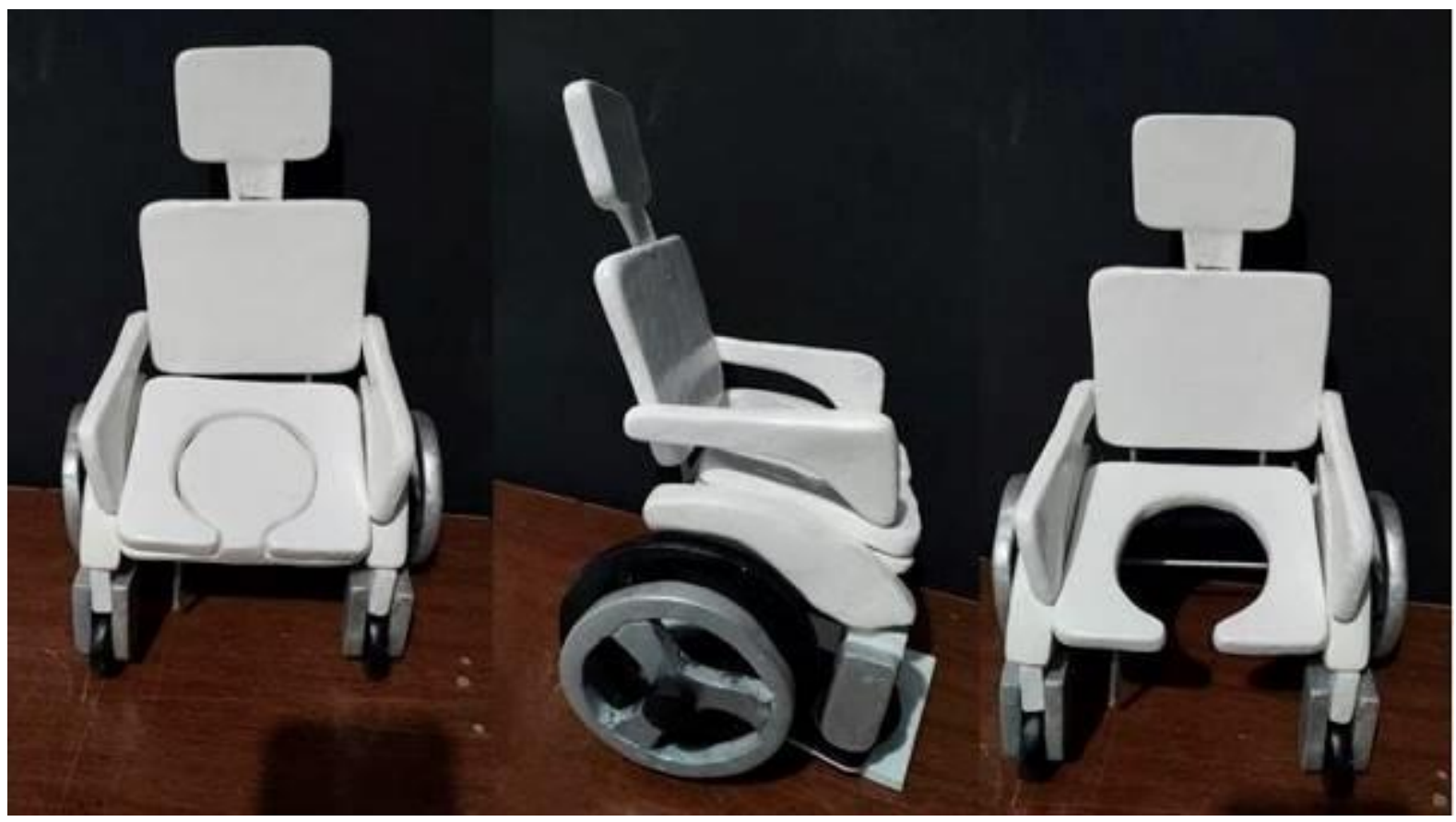

Fonte: Autores (2020)

O produto desenvolvido foi pensado na segurança e no conforto do usuário, sendo o principal diferencial a segurança transmitida a partir dos materiais utilizados, do giro em $360^{\circ}$ e da alça, que se apresenta o formato em barra, permitindo assim facilidade no uso dessa peça. No quesito 
conforto, suas características estão atreladas ao uso das linhas orgânicas, as bordas arredondadas, o material e a ergonomia.

\section{Considerações finais}

Neste projeto, foi possível observar o design atrelado a tecnologia assistiva, sendo importante salientar que no futuro haverá uma grande demanda para produtos voltados ao público idoso, e investir em projetos que sejam direcionados a esse público é um fator significativo. Com o aumento da oferta de produtos específicos para essa faixa etária, pode auxiliar a vida do usuário, trazendo assim, mais conforto, praticidade e independência. Tendo em vista essa situação, buscou-se identificar e entender o problema utilizando uma metodologia híbrida, constituída por várias ferramentas de autores diversos, como forma de solucionar as necessidades da melhor forma possível.

Com a apresentação final da solução gerada, que encerra todo o processo, obteve-se o resultado que foi estabelecido inicialmente, sendo este um projeto de uma cadeira de rodas para banho. Além disso, o aprendizado absorvido durante o processo é claro, o conhecimento sobre a faixa etária estabelecida e a tecnologia assistiva, além do papel do design e do designer na sociedade e contribui para enriquecimento do repertório técnico e empírico.

\section{REFERÊNCIAS}

BAXTER, M. Projeto de produto: guia prático para o projeto de novos produtos. São Paulo: Edgard Blucher, 2000.

BOIANI, Josieli Aparecida Marques; FERREIRA, Ana Cristina Maurício; BOTURA JUNIOR, G.; BONSIEPE, Gui. (coord.). Metodologia experimental: desenho industrial. Brasília: CNPq/Coordenação editorial. 1984.

BUZAN, Tony. Domínio do mapa mental: o guia completo para aprender e usar o pensamento mais poderoso. 1. ed. [S. l.]: Cultrix, 2019. 224 p. ISBN 8531615259.

CADEIRA de Banho em Alumínio e De Uso Misto | SUPERFISIO. [S. l.: s. n.], 2018. Disponível em: <https://www.youtube.com/watch?v=sTJfLxWRxqo〉. Acesso em: 29 nov. 2019.

SARTORETTO, Mara Lúcia; BERSCH, Rita. Tecnologia Assistiva. Disponível em: <http://www.assistiva.com.br/tassistiva.html >. Acesso em: 29 nov. 2019

SAÚDE da pessoa idosa: prevenção e promoção à saúde integral. [S. l.], 2019. Disponível em: https://saude.gov.br/saude-de-a-z/saude-da-pessoa-idosa. Acesso em: 29 nov. 2019

VIANNA, M. et al. Design thinking: inovação em negócios. Rio de Janeiro: MJV Press, 2012 